\title{
Security Management and Operation Mechanism of Digital Libraries in Military Academies
}

\author{
Lili Zhao \\ Library of Primary Flight Training Base College \\ Aviation University Air Force \\ Changchun, China 130062
}

\author{
Lishu Zhang \\ Library of Primary Flight Training Base College \\ Aviation University Air Force \\ Changchun, China 130062
}

\author{
Dake Wang \\ Library of Primary Flight Training Base College \\ Aviation University Air Force \\ Changchun, China 130062
}

\begin{abstract}
This paper discusses the connotation of information resources security of library in military academies in view of the present situation of various forms of resources under the network environment, analyzes the problems that affect the network information security of library in military academies, the factors that affect the network information security, and discusses the construction strategies of the network information security system of library.
\end{abstract}

Keywords—digital library; information security; operating mechanism; military academy

\section{INTRODUCTION}

Under the network environment of library in military academy, the information resources have already broken through the category of traditional document resources and extend to a new library collection system with richer content and more diversified forms. Information resources have been extended from single traditional literature resources to multiple information resources form including traditional literature resources, electronic publication and the network information resources and covering wide scope, making the library lay a more perfect and solid material foundation in the information service and provide the safeguard for better satisfying the user unceasingly increasing information demand. However, the network system has the characteristics of frangibility, complexity and vulnerability, and also brings new challenges to the operation and management of the library. How to make the network information of the library run safely, make the infinite network information resources serve the officers and soldiers quicker and better, take the comprehensive security measures to ensure the information security in the library, and maintain the normal progress of the daily business work of the library and the readers' access to the service has become a realistic problem that we must face.

\section{ANALYSIS OF PROBLEMS IN INFORMATION SECURITY}

The information security of library in military academies means that the hardware and software of network system and the data and running environment of the system are protected from being destroyed, changed and divulged by accidental factors and malicious intention and the network service won't be interrupted. These problems involve various information technology hardware facilities such as computer networks, operating systems, databases, and application systems. Many information security problems have the following characteristics: First is the uncertainty and dynamic of security. The library network of military academies will be visited by internal users with different needs, so its network security is restricted and influenced by many factors. The second is comprehensiveness. The network information security of library in military academies is affected by many factors. Although the scale of military training information network is not as large as that of Internet, it is not easy to ensure its safe, effective and smooth operation. Although headquarter stipulates the "ten no" related to computer, in the process of actual operation and execution, some unexpected things will happen. For example, although the security management system has been installed in all military library network server, many users have different demand for the Internet. Therefore, the security question is not the question purely on technical level, it also relates to the internal management, the external environment, and the users' technology level for computer application. In order to ensure the safety of network information, it is necessary to combine each link closely, consider as a whole and solve the problem one by one. Another is the difficulty of management, because information security is contradictory to "user first". It is necessary to establish a balance between library network information and users. That is, to achieve the best security effect through the combination of control means and management of different technologies. 


\section{FACTORS INFLUENCING NETWORK INFORMATION SECURITY}

Library information resources should be properly protected to avoid being damaged or changed due to internal and external factors. The main factors that threaten the information security of library are the poor information storage environment, the hidden dangers of network security, the mistakes of management measures, and the sense of responsibility of staff.

\section{A. Objective Factors}

First is the poor external environment for information storage. Poor external information storage environment can cause a variety of equipment failure and security risks, accelerate the aging and damage of equipment and network collapse, or cause irreparable trivia. For example, the temperature and humidity of digital library prevention room is not up to standard; the quality of power supply and electrical equipment is stable; there is no monitoring and alarm devices equipped with; there is no safety equipment and measures such as fire prevention, theft-proof, moistureproof, lightning-proof, magnetic field and electrostatic interference. These may bring serious safety accidents to the information of library system.

Next is the hidden danger in network security. The main factors that threaten the normal operation of network information system are in hardware and software. The hardware aspect: the performance or quality of information storage, the operation related equipment or the auxiliary hardware equipment is poor, causing the abnormal operation of information system or the missing data transmission, even the paralysis of entire network. The software aspect: the instability of the network system operation caused by imperfect function of library operation platform system software and other auxiliary software and the incompatible software and hardware; Network system software is easy to be used because of its defects, which brings unexpected hidden dangers to network security. Besides, computer virus will result in great harm by attacking the library network system, including: slow data storage and transmission, occupation of disk space, damage to the normal operation of the system software, and damage to the mainboard and so on.

\section{B. Subjective Factors}

First, the library management and the ordinary librarian have weak information security consciousness and low sense of responsibility, so the supervision and management is weak and the violator is not punished; there are mistakes or loopholes in the development of information security management procedures, which are easy to operate and use; the insufficient investment of information security protection fund in library affects the purchase and maintenance of security equipment.

Second, the librarians lack the professional ethics quality, deliberately sabotage the normal operation of network and the security and integrity of information data, and steal the secret information resources; the failure of the network system is caused by the incompetence or the improper operation of the professional and technical personnel.

Third, the Hacker attacks the library network system maliciously, manipulates and attacks the library server, tampers with the electronic document information of the database, steals the information, and disturbs and slows down the network system.

\section{CONSTRUCTION STRATEGY OF LIBRARY NETWORK INFORMATION SECURITY SYSTEM}

The network information security of library in military academy is not an isolated and static concept, but a multilevel, multi-factor, comprehensive and dynamic process, which runs through the whole process of library information service and the whole life cycle of information system. An excellent information system security strategy must be based on the objective analysis and evaluation of the information system security requirements and the environment. On the basis of the objective analysis and evaluation of the system application performance and security requirements and the environment, an "optimal balance point" between the system application performance and security requirements should be established. Therefore, the protection and establishment of the network information security system of the library should be considered at least from the following aspects:

\section{A. Creating a Good Environment for Information Storage and Operation}

Good information storage environment should meet the basic requirements of many hardware devices for information storage and operation, thereby greatly extending the service life of the information medium and the security performance of the information network.

\section{B. Strengthening Various Technical Means}

The first is to standardize the identity authentication and password protection. To protect the information security of the network system, it is necessary to authenticate the identity, set up all kinds of operation passwords, and change the password periodically. It only is convenient for library personnel to maintain and manage the network system, but also can ensure that the network resources won't be illegally used and accessed.

Second is close monitoring. Strengthening monitoring measures mainly includes the installation of firewalls and security detection system. Firewall technology is the barrier of network security. As the first barrier of network system, it realizes the effective management of network security by controlling and monitoring the information exchange and access behavior between networks. Its basic function can filter in and out the network data; Manage the access behavior in and out of networks; Monitor and audit the access to the network, block some forbidden behaviors, protect the internal network from illegal users, and prevent the internal information from leaking out; record information content and activities through the firewall; The detection system can detect and report unauthorized or abnormal phenomena in time during the scanning and monitoring 
process of the network, and detect and alarm the network attack.

Third is encryption technology. Encryption technology ensures the information and communication security of the network. It uses the technical means to change the important data into random code (encryption) for transmission, and then use the same or different means to restore (decryption) after reaching the destination. It can be used for both information storage and information transmission so that it is not recognized by the unauthorized party.

Fourth, we should take a backup strategy. Data backup is an important remedy for library information security. The data of the system can be stored on the file server of this computer, or stored on the optical disk and the mobile hard disk. When security accidents occur in the operation of information data and the storage, it can quickly restore the normal network service.

Fifth is to resist the network virus. By installing antivirus software and hard disk protection card on the network server and workstation, it can effectively resist all kinds of viruses to invade the computer network. Attention should be paid to combining the hardware firewall and software firewall and anti-virus software, and isolation zone should be established to prevent the invasion of the virus. At the same time, hardware and software firewall and the virus database of the anti-virus software should be updated regularly, and various measures should be taken to prevent the virus from entering the library system.

\section{Continuously Improving Library Management Mode and Level}

We need to strengthen the safety consciousness of all the staff of library, enhance the responsible function of library leaders at all levels in information security, and improve the level of supervision and guidance; According to the different nature of librarian's work, it is necessary to make the duty clear and the responsibility come to the person. Regular security inspection, assessment and learning should be carried out to continuous summarize and improve safety management methods and technical level.

\section{Continuously Improving Library Information Security Management System and Strictly Implementing Library Operating Rules}

Librarians must fulfill the full-time specialized duty, strictly forbids to operate overstepping the level and post; strengthen the special management of the main control and other equipment, and improve the access permit system; regulate the approval and monitoring system for the use of external mobile media and the loan of hardware equipment; perfect the management system for system software, the application software and the tool software, and strengthen the database quality control management system and so on, to ensure the safe, efficient and orderly operation of the library information system.

\section{E. Establishing Risk Prevention Plan for Information Security}

According to the unexpected events that may occur in the information security of the library, the risk prevention plan should be established. Risk prevention plan mainly includes risk aversion, restraint and remediation measures, and strives to minimize the level of loss. The feasible plan includes: plan for book, equipment and personnel to deal with the fire, accident alarm and first aid, remedy plan for network hardware and software fault and so on.

\section{F. Protecting the Information Security of Digital Library by Using the Technology of Information Encryption and Digital Watermarking}

The purpose of information encryption is to protect the data, files, and passwords and control information in the network, and protect the data transmitted on the network. There are three common methods of data encryption: link encryption, endpoint encryption and node enhancement. The purpose of link encryption is to protect the security of link information between network nodes. The purpose of endpoint encryption is to protect the data from the source end user to the destination end user. The purpose of node encryption is to protect the transmission link between the source node and the destination node. In most cases, information encryption is the only way to ensure the confidentiality of information. An encrypted network not only can prevent unauthorized users from eavesdropping and accessing the network, but also is one of the effective methods against malicious software.

\section{G. Strengthening Security Education and Improving the Awareness of Network Information Security}

The lack and fuzziness of the awareness of network information security is a major difficulty for the library in military academies to carry out the work of network information security management. Although many comrades can use and manage, they can't prevent and know very little about the security maintenance of network information. They always think that their library is a small local area network, so the security problem should be the affairs of the superior website. Therefore, it has become a top priority to improve the information security awareness of network security managers and all users, popularize the knowledge of security protection, and improve the technical skills of network information protection. Only through publicizing and correcting the wrong understanding of ignoring network information security, information security management can be solid and effective.

\section{H. Establishing and Perfecting the Relevant Systems and Regulations to Maintain the Network Information Security of the Library}

With the widespread popularity of computers and the rapid development of network technology, It is necessary to make overall planning for the network security management of library in military academies and make a quick response and decision to the major network information security events faced by the library, put forward the network 
information security planning of the library, organize and formulate the codes and standards of the network information security, carry out information monitoring to the network information flow, and make a quick response to the harmful information. Every library must develop a sound management system, including establishment of a good user awareness and password management mechanism. According to the requirements of network operation, the user login password and the network user password of the application system can be adopted, and different start-up password and entry password of system software are set for each machine. Secondly, it is necessary to establish and perfect the information security system of the library. From a systematic and comprehensive perspective, we should establish and perfect the network security management system, and implement all the security measures and procedures of the library through the methods and means of the management system. It mainly includes the following aspects: management system for operating personnel, management system for operating technology, virus protection system, equipment management and maintenance system, software and data management system. Third, we should strengthen the security protection system, and do well in environmental construction. This mainly refers to strengthening the security management of computer and the system, such as the security of computer room, terminals, network control room and other places.

\section{Strengthening the Training of Network Information Security Professionals in Libraries}

At present, the network information security talents in the libraries of military academies are rare, and it is good for each library to have a person who knows network information security well. In the short term, these talents can't meet the needs of network information security. Therefore, libraries need to strengthen the training of network information security professionals, and vigorously cultivate the backbones who comprehensively master the network information security skills.

\section{CONCLUSION}

In a word, the security of digital library is a complicated systematic project. While developing the security technology of digital library, we should strengthen the education of people's security consciousness and moral education constantly, and restrain all kinds of behavior from macroscopic and microscopic angle to make people maintain and obey the order of digital library conscientiously. The key to the security is people. Only when the security consciousness of people is improved, the security of digital library can be guaranteed to the greatest extent, the network information security of the library of our military academy can be guaranteed, and the more solid guarantee can be provided for the various business work of digital library.

\section{REFERENCES}

[1] Zeng Xianfu. Library Network Security and Its Countermeasures [J] Public Library, 2009, (2). 曾宪付. 图书馆网络安全及其应对策略 [J] 公共图书馆, 2009, （2）

[2] Wang Hongjuan. The hidden trouble of network security in university library and its prevention [J]. Information Research, 2009, (5). 王洪 娟.高校图书馆网络安全隐患与防范[J].情报探索，2009，（5）

[3] Niu Yanrong. Research on Information Security Measures of Digital Library [J]. Science and Technology Innovation Herald, 2010, (23). 牛艳蓉.数字图书馆信息安全措施研究 [J].科技创新导报, 2010, (23)

[4] Wang Liling. On the Security of Digital Library [J]. Science \& Technology Information, 2010, (3). 王丽灵.试论数字图书馆的安全 问题 $[\mathrm{J}]$.科技信息，2010，（3）

[5] Luo Qifeng. Research on network security of university library [J] Library Tribune, 2008, (7). 骆奇峰. 高校图书馆网络安全问题研究 [J].高校图书馆论坛，2008，（7） 